originating from the cornea are not abolished. This shows that the adrenergic and sensory nerve fibres concerned, although exposed to the same concentration of toxin within the eye, are not affected in the same way as are the cholinergic fibres.

In similar experiments. on voluntary (extrinsic ocular) muscles paralysed with toxin, normal responses to acetyloholine were recorded. This differentiates the botulinic effect on skeletal muscle from that of curare poisoning, and again points to a lesion of the motor nerve-endings which are cholinergic.

Lastly, it has been found that despite its high molecular weight $\left(900,000-1,130,000^{2}\right)$, this protein is able to pass out of the eye into the general circulation, which suggests that it must be capable either of inducing a change in capillary permeability to allow its passage, or that it is broken down to a smaller diffusible molecule which is still neurotoxic.

It is hoped to publish a full account of this work elsewhere, and further investigations are in progress.

Institute of Physiology,

University College,

London.

Jan. 12.

${ }^{1}$ Edmunds, C. W., and Long, P. H., J. Amer. Med. Assoc., 81, 542

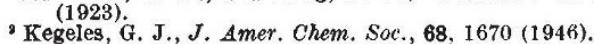

\section{Secondary Thickening in Excised Tomato Roots}

WHITE ${ }^{1}$ has stated that secondary thickening does not occur in excised root cultures. Some of our cultures of tomato ('Best of All') which had been kept without transfer for five to six months were recently submitted to anatomical investigation, and were found to have developed a considerable amount of secondary xylem, though the occurrence of properly differentiated secondary phloem has not yet been demonstrated. The nature and extent of the secondary xylem can be illustrated by reference to two examples.

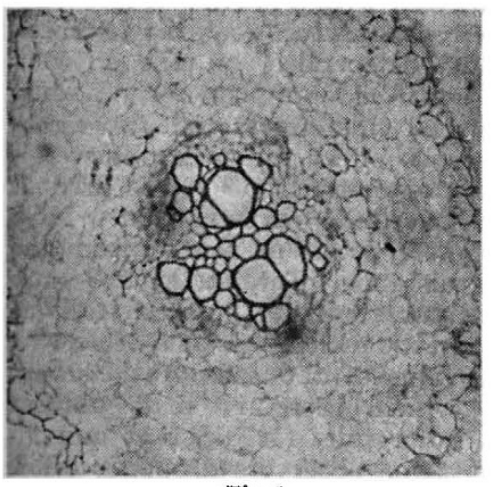

Fig. 1

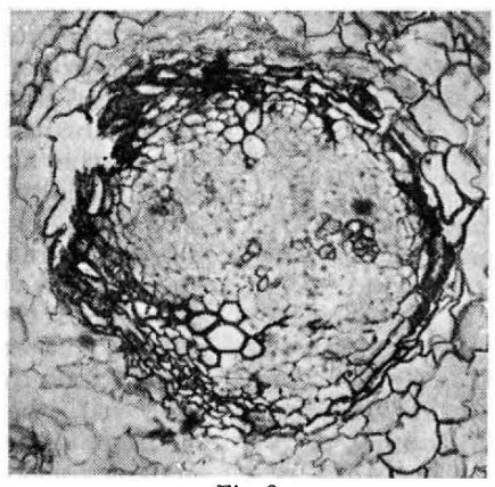

Fig. 2 central mass of thin-walled cells, the whole clearly formed by the activity of a cambium-like layer.

Culture Passage 1, No. 13, growing on White's yeast medium, also yielded some sections with normally distributed secondary xylem and others showing pronounced abnormality (Fig. 2). Here, on one side of the diarch primary xylem, repeated and disorderly cell divisions have produced a mass of callus-like tissue, only a few cells of which are differentiated into xylem elements. On the other side of the primary xylem, no corresponding development has occurred.

These examples demonstrate the occurrence of secondary xylem, but also show that the cambial activity is frequently seriously disorganised and results in the production of conspicuously abnormal structures. The exact age at which secondary thickening begins and the extent to which the process is influenced by cultural conditions are now under investigation, and will form the subject of a sub. sequent report.

\section{Department of Botany, University College, Nottingham.} Dec. 11.

' White, P. R., "A Handbook of Plant Tissue Culture", 159 (1943).

\section{Second Occurrence and Persistence of the Amphipod Orchestia bottze M. Edwards in Britain}

THE amphipod Orchestia bottce M. Edwards was first recorded in Britain by Gordon ${ }^{1}$, who found it on the banks of the Thames at Richmond in 1942. This species, from the Mediterranean area, appears to be spreading and invading the freshwater systems of Europe. Dr. Gordon quotes records of its being taken in France (Cambrai, Nancy), Holland (80 $\mathrm{km}$. from the sea), Belgium and Germany. The object of this note is to record that in July 1946 we found it in large numbers, adult and very young, in the damp roots of grass just above the water on the right bank of the Thames at Oxford, about half-way between Folly Bridge and Iffley Bridge ; this is 92 miles upstream from the first lock (Teddington). In July 1947, one of us (A. J. C.) found it again in the same spot, still quite abundant though perhaps less so than in 1946. The severity of the spring had not apparently affected it.

We are indebted to Dr. G. M. Spooner of Plymouth for identifying our specimens. Dr. Gordon, of the British Museum, who has also seen

specimens, confirms that it is
the same species as that found by her at Richmond

Root culture Passage 5, No. 41, growing on White's synthetic medium, exhibited in its older parts a patchy brown discoloration accompanied by a distinct thickening. Sections of these regions contained considerable quantities of secondary xylem. Most of the sections were characterized by an almost normal distribution of secondary xylem (Fig. 1), though some showed an anomalous condition in which a ring of lignified tissue containing vessels enclosed a in 1942 .

\begin{tabular}{|c|c|}
\hline & $\begin{array}{l}\text { A. J. CaIN } \\
\text { D. H. CUSHING }\end{array}$ \\
\hline $\begin{array}{c}\text { Department of Zoology an } \\
\text { Comparative Anatomy, } \\
\text { Oxford. } \\
\text { Dec. } 10 .\end{array}$ & \\
\hline
\end{tabular}

